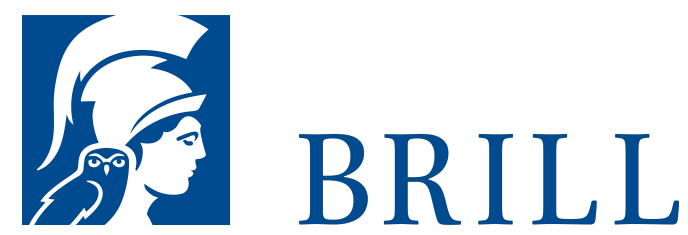

\title{
Zur heuristischen Qualität des Reduktionismus
}

\section{Author: Fabian Lausen}

In der wissenschaftsphilosophischen Reduktionismusdebatte geht es um die Frage, ob die Vielfalt wissenschaftlichen Wissens aus der Beschäftigung mit einer grundlegenden Ebene von Objekten (etwa Elementarteilchen oder Molekülen) abgeleitet werden kann. Dabei geht man meistens davon aus, dass die Frage nach der prinzipiellen Möglichkeit einer solchen Herleitung der eigentlich interessante Gesichtspunkt sei, diejenige nach dem praktischen Nutzen dementsprechender Forschungsstrategien jedoch nur zweitrangig. Im Gegensatz zu dieser vorherrschenden Meinung rückt dieses Buch die zweite Frage in den Vordergrund. Der Reduktionismus wird dabei durch die Interaktion zwischen drei Forschungsstrategien charakterisiert: Konstruktion von Identitäten, Dekomposition und Vereinheitlichung. Mithilfe dieses Zugangs wird eine differenzierte Beurteilung des praktischen Nutzens des Reduktionismus ermöglicht. Dabei wird der Reduktionismus als ein vielseitiges Werkzeug mit vielen Stärken und Schwächen erkannt, das nicht allein aufgrund prinzipieller Überlegungen letztgültig akzeptiert oder verworfen werden sollte.

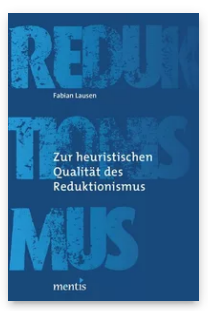

Pages: 244

Seiten

Language:

German

Subjects:

General,

Philosophy

Publisher: Brill | mentis

E-Book (PDF)

Released online: 25 Apr 2014

ISBN: $978-3^{-}$ 89785-99o-6

List price

Paperback

Publication date: 25 Apr 2014

ISBN: 978-389785-989-о List price 
For more information see brill.com

Order information: Order online at brill.com +44330 333 0049 | customerservices@brill.com Submission information: brill.com/authors

Titles published by Brill | Fink, Brill | mentis or Brill | Schöningh: +49(o)715413279216| brill@brocom.de 